\title{
NUMERICAL SIMULATION OF TWO-PHASE FLOW IN AN EFFERVESCENT ATOMIZER WITH BIOFUEL APPLICATION
}

\author{
S. A. Wilson, A. R. Syam, A. Helmy, A. Balabel \\ Mechanical Power Engineering Department, Faculty of Engineering \\ Menoufiya University, Shebin El-Kom, Egypt
}

\begin{abstract}
The Effervescent atomizer, which is a type of internal-mixing twin-fluid atomizer, has been showed to work well with biofuels in terms of lower droplets size at relatively low injection pressure. The two phase flow inside the atomizer was numerically simulated using the volume of fluid model. Validation with experimental work was performed. The present results showed that the gas to liquid mass ratio (GLR) is one of the major contributory factors affecting the atomizer performance. The two phase flow was identified as slug flow in the discharge passage at low GLR $(.08 \%)$. The flow evolved to slug- annular flow at GLR $=0.5 \%$. At relatively high GLR (0.8\%) the annular flow was distinguished. The mixing between phases was augmented with increasing GLR. Finally the liquid film thickness at the atomizer outlet was calculated and compared with the conventional aviation Jet-A1 fuel. The results showed that the liquid film thickness almost remains unchanged at low GLRs, though the higher biofuel viscosity, order of four. But, for higher GLRs, the liquid film thickness slightly changed. Finally, the results unveil the superiority of effervescent atomizer with Jatropha biofuel.
\end{abstract}

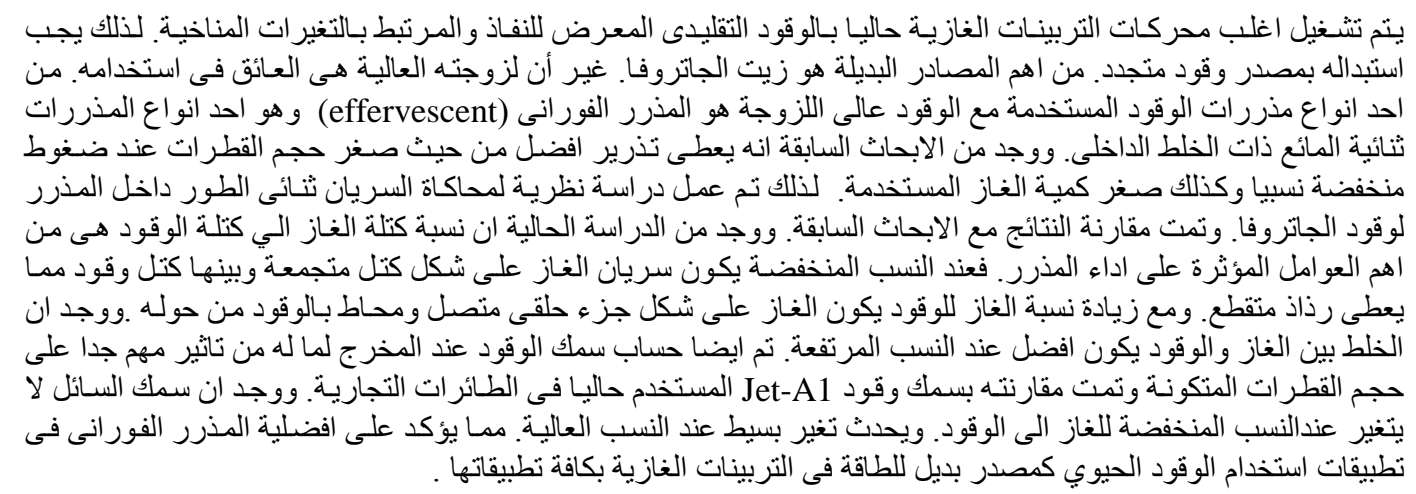

Keywords: Jatropha; biofuel; effervescent atomizer; liquid film thickness; volume of fluid; two phase

\section{INTRODUCTION}

Power generation is the backbone of all human activities. One of the most important power generation sources is the gas turbine engines, due to their wide power range and compact size. Unfortunately, today most of gas turbine engines depend on the combustion of fossil fuels, which is accompanied with bad environmental effects and energy crisis issues [1]. Even though, we cannot replace the combustion process as a power source, but the fuel to be combusted [2] avoiding major changes in current engines designs.

One of the promising alternatives is Jatropha biofuel [3]. This is due to its sustainability and ability to be cultivated in deserts with only rain or even sewage water. But using biofuel in gas turbine engine faces several challenges, due to the high viscosity and surface tension of relevant biofuel [4]. This leads to bad atomization characteristics in terms of larger droplets size and low mixing rates which inhibiting complete combustion. From the literature, there are three distinct techniques to enhance the atomization of high viscosity liquids as biofuel. The first technique employs heating to reduce liquid viscosity [5]. But heating the fuel requires precise control in order not to affect the chemical properties of the fuel and avoiding thermal break-down of the fuel. The second technique depends on blending biofuel with 


\section{S. A. Wilson, A. R. Syam, A. Helmy and A. Balabel "Numerical Simulation.."}

fossil fuel. But it is still dependent on fossil fuel which is limited [6] and the change in properties depends on mixing ratio. The effective technique may depend on using special types of atomizers dedicated for high viscosity fuels [4]. From various atomization techniques, effervescent or Aeratedliquid atomization [7-9] showed good atomization characteristics with high viscosity liquids.

The basic idea of effervescent atomizer is by loading the bulk liquid with bubbles of the atomizing gas upstream of the atomizer exit [7] to form twophase bubbly mixture. Similar to the trapped air bubbles in an opened water tap, the bubbles explode just at the exit of the atomizer which enhances liquid shattering and atomization. The presence of gas bubbles has three main effects; first, due to the lower gas density, the gas occupies larger portions in the discharge passage and squeezing the liquid thickness which augments the atomization. Second, the liquid velocity is increased as a result of the reduction in liquid flow area leading to better atomization [7]. Third, on exiting the discharge passage the gas bubbles rapidly explode, due to sudden pressure relief, shattering the bulk liquid into ligaments and drops [7].

Compared with conventional atomizers, effervescent atomizer shows worth-mentioned advantages such as; good atomization characteristics, in terms of smaller droplets size, with relatively low injection pressures $[7,8]$, small amount of atomizing gas, as only needed from the atomizing gas is to occupy some volumes inside the liquid in the form of bubbles [8], larger discharge orifices can be used reducing orifice clogging and erosion [7], the fuel properties have slight influence on the atomizer performance, allowing usage of different fuels [9]. Good atomization characteristics can be achieved even with high viscosity liquids [9].

In view of its relevant advantages, effervescent atomizer can be used in many application fields [10] such as internal combustion engines, furnaces and burner, gas turbine engines, ram jet engines, pharmaceutical spray, fire suppression and spray coating applications.

As being a type of twin fluid atomizers, the internal flow inside effervescent atomizer affects the atomizer performance and the corresponding produced spray to great extent [10]. Even though, a lot of studies have been made to investigate the external flow. However, fewer studies were conducted on the internal two-phase flow inside the atomizer. This may be attributed to the difficulties associated with flow in micro channels and the relevant complex physical phenomena [10].
The early attempt to study the internal flow inside effervescent atomizers was performed by Roesler et al [11]. They used the visualization technique to identify the internal flow inside a transparent effervescent atomizer. Further, measurements for spray SMD were performed. They used water and air as the working fluids. Three flow regimes were observed with increasing GLR; bubbly, slug and annular flow. Further they noticed unsteadiness of spray in slug regime. They confirmed remarkable decrease in SMD with increasing GLR.

Chin and Lefebvre [12] employed previous available data concerning the two-phase flow in pipes to the flow inside effervescent atomizers. By this method, they were able to investigate internal flow transitions and effects of operating parameters. They plotted the data concerning the internal flow in the form of flowmaps. Flow regimes with lines distinguishing different flow regimes were characterized. By using these maps, they could predict the flow transition from bubbly, slug and annular flow with increasing GLR. For very high GLR they predicted liquid to flow as suspended droplets in the gas stream on exiting the nozzle. They also predicted that either increasing liquid viscosity or injection pressure would promote bubbly flow regimes. The main drawback of the developed maps is that they were based on data extracted for fully developed flow in pipes which is not coincide enough for effervescent atomizers.

By using imaging technique, Lin et al [13] performed a comprehensive experiments on the flow inside a transparent effervescent atomizer, embracing the variations of aerating tube configuration, converging angle connecting mixing chamber and discharge passage, discharge passage length and the effect of aeration levels. They concluded that the internal flow regimes have a great influence on the corresponding produced spray. The results showed the transition in internal flow structures from bubbly flow in the mixing chamber to slug flow in the final passage, to a co-annular flow as the aeration level increases. They also observed that the co-annular flow regime, obtained at high aeration level, results in more spray steadiness and better atomization. A correlation relating liquid film thickness in discharge passage with GLR was fitted.

In agreement with the observations done by Lin et al [13] and Huang et al [14], Locher et al [15] distinguished between main flow regimes in the discharge passage, bubbly, slug and annular flow with increasing aeration levels. They measured the gas void fraction inside the mixing chamber and the exit nozzle of an effervescent atomizer using electrical tomographic technique. They noticed that 


\section{S. A. Wilson, A. R. Syam, A. Helmy and A. Balabel "Numerical Simulation.."}

gas bubbles elongate and expand in the discharge passage due to the increase in velocity.

In order to investigate the compatibility with biofuels, Madan et al [16] performed experimental study on the the characterization of effervescent spray of Jatropha biofuel. They used imaging technique and direct measurements of SMD using PDIA. The biofuel results were compared with conventional diesel fuel. They concluded that at very low GLR, the biofuel is not atomized well and intact ligaments can be distinguished compared to better atomization for diesel at same GLR. But increasing GLR improves the atomization of biofuel. Also they noticed that increasing injection pressure augments biofuel atomization at low GLRs. Trapped gas bubbles were observed in intact liquid jet at low GLR due to the high viscosity of biofuel. But increasing GLR gives these bubbles enough power to explode against liquid forces. However, Even though biofuel requires higher GLR, it is still incomparable with the excessive GLR associated with other twin fluid atomizers. In view of the difficulties accompanying experimental work on two-phase flow, several numerical simulations were performed to investigate two-phase flow evolution inside effervescent atomizer. Tian [17] conducted a numerical simulation using mixture model to simulate the two-phase laminar flow in an aerated-liquid injector configuration based on the experimental work of Lin et al. [13]. The model was tested for two different cases of GLRs and the results were compared with the experimental data. The results were somehow far from the experimental results of Lin et al. [13]. This can be attributed to the 2-D geometry simplification adopted, which does not match with the actual atomizer geometry. Furthermore, two different choices for the surface tension were tested, the choice of reference velocity, the type of inflow boundary conditions were also investigated.

Esfarjani and Dolatabadi [18] used the EulerianEulerian two-fluid model to simulate the threedimensional structure of two-phase laminar flow inside the effervescent atomizer of the experimental of Lin et al [13]. The Multi-Fluid Marker and Cell (MFMAC) method was used. The behaviour of liquid film in the discharge passage was investigated using different gas-to-liquid mass flow ratios (GLR), ranging from $0.08 \%$ to $1.25 \%$. It was found that the liquid film thickness is slightly independent of liquid physical properties such as density and viscosity. The 3D Iso-surfaces of gas phase revealed that the gas flow is in the form of separated bubbles generated inside the mixing chamber, and evolved on their way toward the discharge passage. By increasing the aeration level, the mixing between the gas and liquid is enhanced and the flow structure near the nozzle exit will be changed from slug flow to co-annular flow. At this flow regime, it was expected to have more uniform and stable spray compared to the cases with lower GLRs. Mehmood et al [19] investigated the use of the Volume of fluid (VOF) technique using ANSYS FLUENT to simulate the internal flow inside the effervescent atomizer used by Esfarjani et al [18]. The flow structure was observed during the simulations at various gas-to-liquid mass flow ratios (GLR) ranging from $0.08 \%$ to $1.25 \%$. It was observed that at low GLR of $0.08 \%$ the gas phase in the mixing chamber can be identified as relatively large bubbles flowing in the liquid phase. The large bubbles evolve into large slugs of gas while entering the discharge duct. At higher GLR of $1.25 \%$, sufficient gas-liquid mixing is achieved in the mixing chamber. Even though a lot of numerical studies have been performed on the two phase flow inside effervescent atomizer, none of these studies have investigated the potential of biofuel as alternative fuel. So the present work aims to numerically investigate the applicability of effervescent atomizer to handle Jatropha biofuel as alternative fuel in one of the most important gas turbine engines application field, the commercial aviation.

In the current study, the configuration used in the Air Force Research Laboratory (AFRL) [13] was modeled to numerically investigate the structures of the internal flow inside effervescent atomizer with Jatropha biofuel. Further, evolution of flow and the liquid film thickness in the discharge passage were investigated. The results were compared with conventional commercial aviation fuel Jet A-1. The results for liquid film thickness in the discharge passage were further validated with experimental data available in the literature.

\section{GOVERNING EQUATIONS}

For isothermal flow, considered in this study, only the conservation of mass and momentum are applied. For turbulence, the realizable k- $\varepsilon$ model [20] was selected, according to the work of Mehmood et al [19]. In addition, supplementary equation representing the volume of the two phases is incorporated in the VOF model [21]. The equations for continuity, momentum and volume fraction, in compact form, are as follow;

$$
\begin{aligned}
& \frac{\partial \rho \phi}{\partial t}+\left(\frac{\partial}{\partial x} \rho u \phi+\frac{\partial}{\partial y} \rho v \phi+\frac{\partial}{\partial z} \rho w \phi\right) \\
& =\left(\frac{\partial}{\partial x} \Gamma_{\phi} \frac{\partial \phi}{\partial x}+\frac{\partial}{\partial y} \Gamma_{\phi} \frac{\partial \phi}{\partial y}+\frac{\partial}{\partial z} \Gamma_{\phi} \frac{\partial \phi}{z}\right) \\
& \quad+S_{\phi}
\end{aligned}
$$




\section{S. A. Wilson, A. R. Syam, A. Helmy and A. Balabel "Numerical Simulation.."}

Where $S_{\phi}$ represents the source term and $\phi$ is general variable to be solved. The values of $\phi, S_{\phi}$ and $\Gamma_{\phi}$ are given in table (1) for each corresponding equation.

The equation of turbulent kinetic energy and turbulent dissipation rate are described in more details by Shih et al [20].

\section{SURFACE TENSION MODELING}

Surface tension is one of the most effective parameters controlling bubbles and droplets diameters in gas -liquid flows. Therefore, modelling the surface tension is necessary for accurate interface tracking. One of the most used surface tension models is the continuum surface force model of Brackbill et al. [22]. In this model, a balance between pressure drop across the surface, due to surface tension, and surface tension force is performed, considering only the normal forces. The surface tension is calculated by getting the curvature of the interface at two radii; R1 and R2. Then the following equation was deduced;

$p_{2}-p_{1}=\sigma\left(\frac{1}{R_{2}}+\frac{1}{R_{1}}\right)$

Where $p_{2}-p_{1}$ represent pressure jump across the interface due to surface tension. Following, the source term due to pressure jump across the interface as a result of the surface tension is incorporated in the momentum equations as follow;

$f_{\sigma}=\sigma \frac{\rho \kappa_{i} \nabla \alpha_{i}}{0.5\left(\rho_{i}+\rho_{j}\right)}$

Where $f_{\sigma}$ is the source term due to surface tension, $i, j$ refers to the phases and $\kappa$ is the curvature normal to the interface.

Table (1). Governing equations for the VOF model.

\begin{tabular}{|c|c|c|c|}
\hline equation & $\phi$ & $\Gamma_{\phi}$ & $S_{\phi}$ \\
\hline continuity & 1 & 0 & 0 \\
\hline momentum & $\vec{U}$ & $\mu_{\text {eff }}$ & $-\frac{\partial p}{\partial x}+\mu_{\text {eff }} \nabla \vec{U}+\rho g+f_{\sigma}$ \\
\hline $\begin{array}{c}\text { volume } \\
\text { fraction }\end{array}$ & $\alpha$ & 0 & 0 \\
\hline
\end{tabular}

\section{ATOMIZER GEOMETRY}

Following the work of Esfarjani et al. [18] and Mahmoud et al [19], the fourth configuration used in the Air Force Research Laboratory (AFRL) by Lin et al. [13] was modelled in the current simulation. The modelled effervescent atomizer has rectangular cross section. The atomizer dimensions are; mixing chamber with $6.4 \times 2 \mathrm{~mm}$ cross section, converging angel of 50 degree, square discharge passage of $2 \times 2 \mathrm{~mm}$ with length $40 \mathrm{~mm}$ and circular aerating tube with internal diameter of $760 \mu \mathrm{m}$ and located at $25.4 \mathrm{~mm}$ upstream of the entrance of discharge passage. The total atomizer length is $85.4 \mathrm{~mm}$.

Further, to account for the relevant physical phenomena such as vortex shedding, the atomizer geometry was extended to include the inlet section for both phases. Therefore, $20 \mathrm{~mm}$ inlet section was modelled in addition to the mixing chamber and discharge length. The thickness of the aerating duct is $350 \mu \mathrm{m}$ and the aerating duct is rectangular in shape with cross section of $0.67 \times 2 \mathrm{~mm}$ [18]. Figure (1) shows the $3-\mathrm{D}$ isometric of the effervescent model and the main dimensions.

\section{COMPUTATIONAL DOMAIN AND BOUNDARY CONDITIONS}

For more realistic results, 3-D simulation is essential to capture the asymmetric behaviour of the two-phase flow. However, symmetrical (x-y) plane was assumed for simplification. Only one half of the domain was modelled [18], as shown in figure (1). For meshing, structured quad grids was adopted. However, for complex domains, decomposition of the domain into blocks is preferred. So, the atomizer geometry was partitioned into 24 subdomains. The total number of cells was around 0.6 million cells. Further, the mesh was clustered near the walls. For inlet, velocity-inlet boundary condition was selected for both phases, shown in figure (2). The inlet velocity was calculated from the corresponding mass flow rate and the inlet area. The value of the inlet volume fraction was given either 0 or 1 according to the dominant phase. For outlet, pressure outlet boundary condition with 1 atm. was selected. Symmetry boundary condition was selected for symmetry plane shown in figure (1). No-slip and stationary boundary condition was selected for all the encountered walls, figure (2). 


\section{S. A. Wilson, A. R. Syam, A. Helmy and A. Balabel "Numerical Simulation.."}

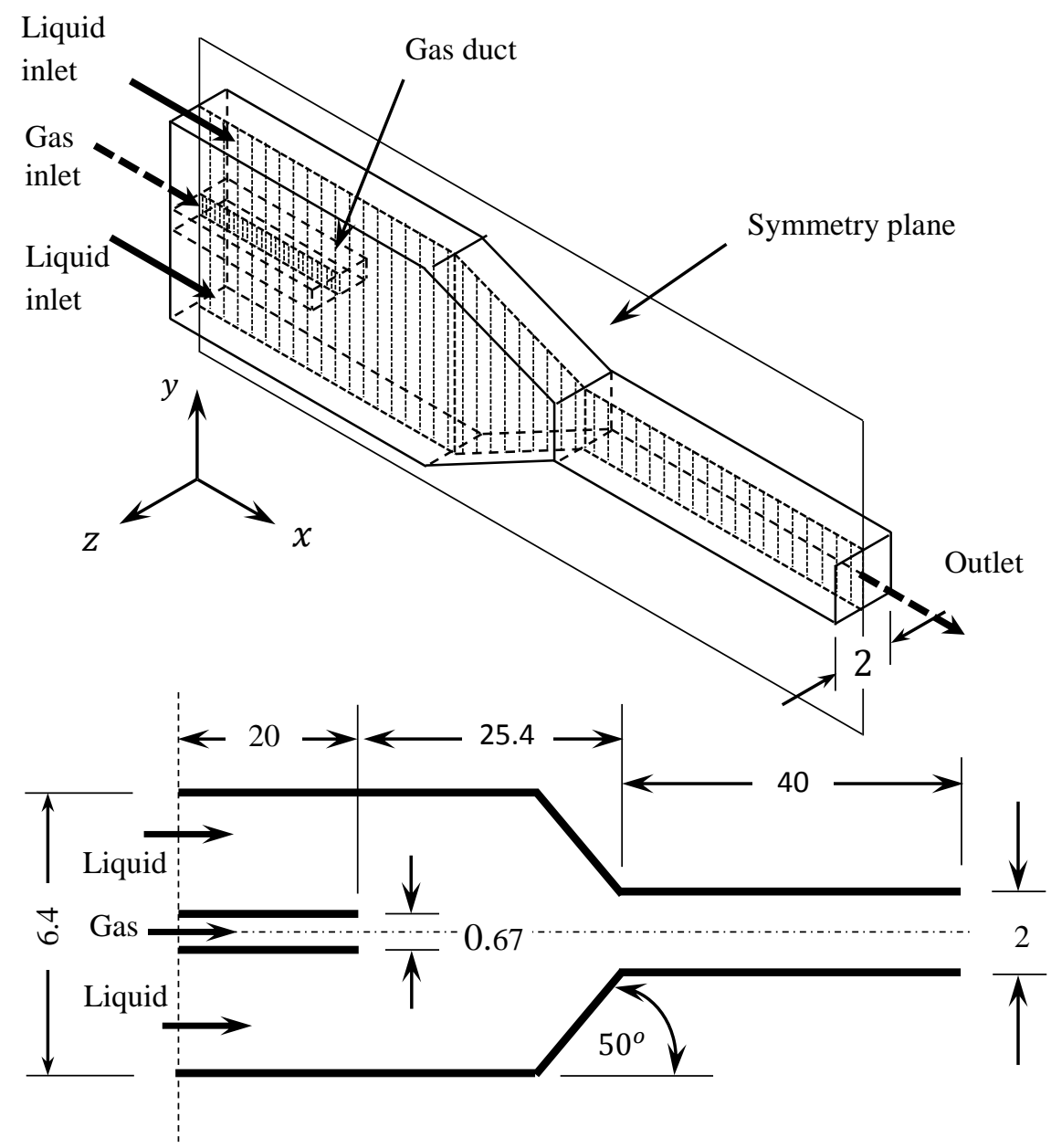

Figure 1. Details of effervescent atomizer model used in present work (dim. in mm)

\section{NUMERICAL METHODOLIGY}

The finite volume approach was used to discretize the corresponding governing equations. The VOF explicit module in ANSYS FLUENT-15 [23] was selected for unsteady incompressible two-phase modelling. Pressure based solver was used. The first order implicit formulation was used for time discretization. For convergence criteria, the second order upwind scheme [24] was selected in momentum, turbulent kinetic energy and turbulent dissipation rate. For volume fraction equation, the Geo-Reconstruction method [24] was selected for accurate interface tracking. The value of courant number was set to 0.25 and the time step was varied

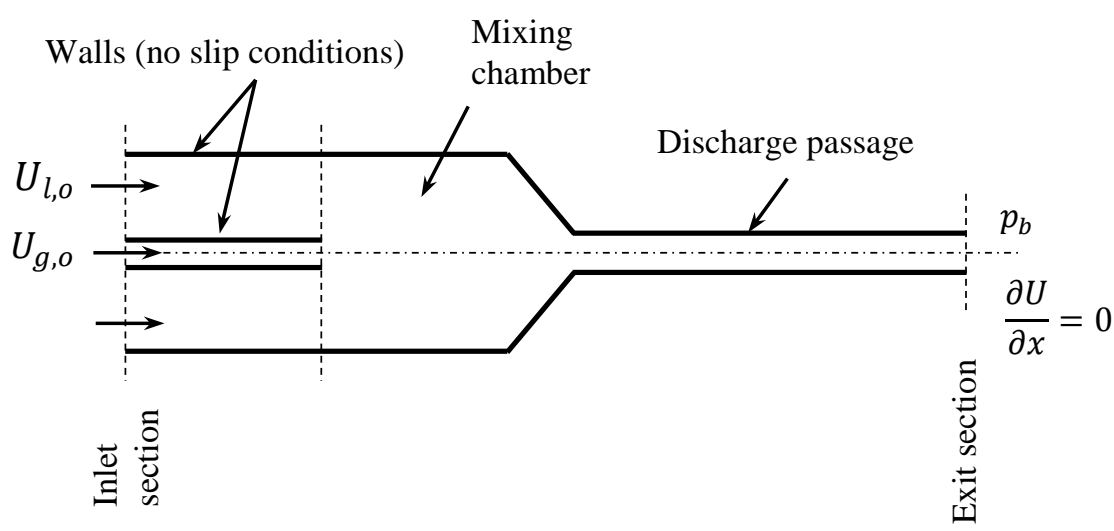

Figure.2 Boundary condition encountered. 


\section{S. A. Wilson, A. R. Syam, A. Helmy and A. Balabel "Numerical Simulation.."}

to maintain the specified courant number.

SIMPLE algorithm was adopted for pressurevelocity coupling for convergence criteria. The enhanced wall function was selected for near wall treatment.

\section{RESULTS}

\subsection{Model Validation}

The first step towards realistic simulations is to check the generality and the applicability of the numerical issues applied to the current analysis. So results validation is a prerequisite. From the literature, the experimental work of Lin et al [13] was selected for validation, due to availability of reliable measurements of void fraction and internal flow related to the modelled effervescent atomizer. They used water as a liquid and nitrogen as aerating gas.
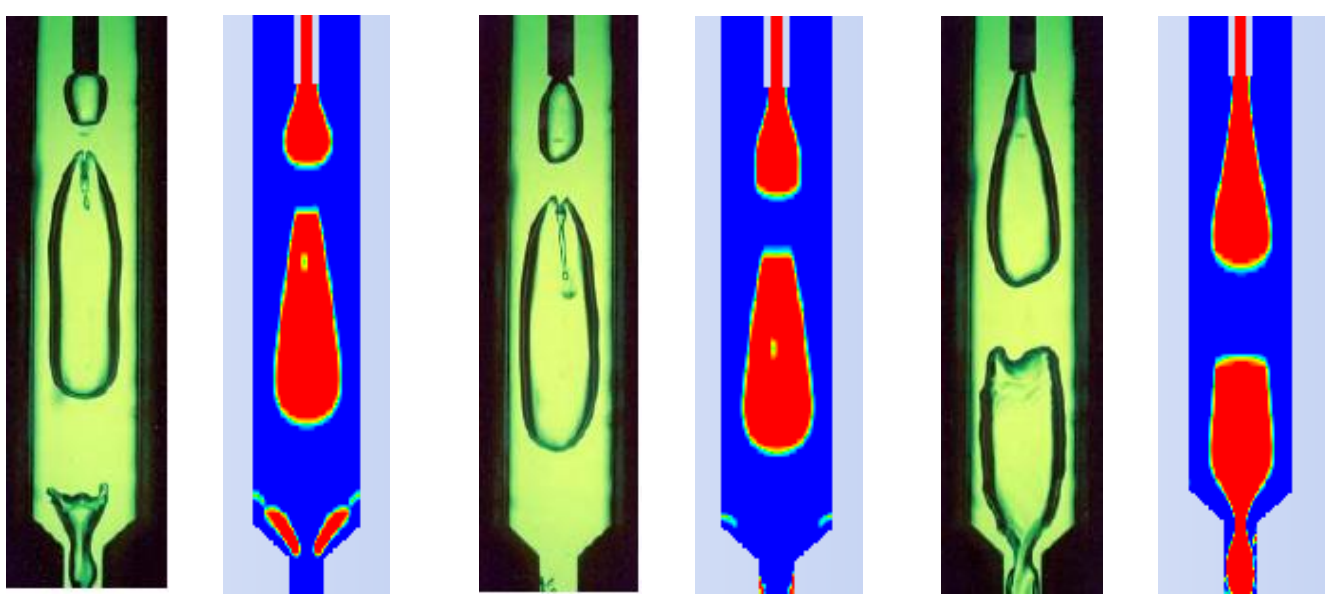

Figure.3 Comparison between gas void fraction simulation results and experimental photo for $\mathrm{GLR}=0.08 \%$ and $\mathrm{QL}=0.38 \mathrm{~L} / \mathrm{min}$ [13].
Figure (3) shows the numerical results of void fraction compared with the experimental photos of the internal flow for liquid flow rate of $0.38 \mathrm{~L} / \mathrm{min}$ and $0.08 \%$ GLR. Even though the lack of experimental measurement time for precise comparison, the results somehow match the experimental photos to great extent. Further, for realistic quantitative comparison, the liquid film thickness calculated according to Esfarjani et al [18] was compared with the experimental correlation of Lin et al [13].

The liquid film thickness was calculated by assuming the aerating gas flows in cylindrical passage of diameter $D_{g}$ and surrounded by annular liquid film of thickness $h$ [19], calculated by;

$$
h=\frac{1}{2}\left(D_{h}-D_{g}\right)
$$

where $D_{h}$ is the hydraulic diameter of the discharge passage $(2 \mathrm{~mm})$. The gas passage diameter $D_{g}$ is calculated from the gas void fraction at exit as follow;

$$
D_{g}=D_{h} \sqrt{\alpha_{g}}
$$

where $\alpha_{g}$ is the average void fraction at exit cross section. The area weighted void fraction was sampled with solution time and then averaged over time period of 5 milliseconds.

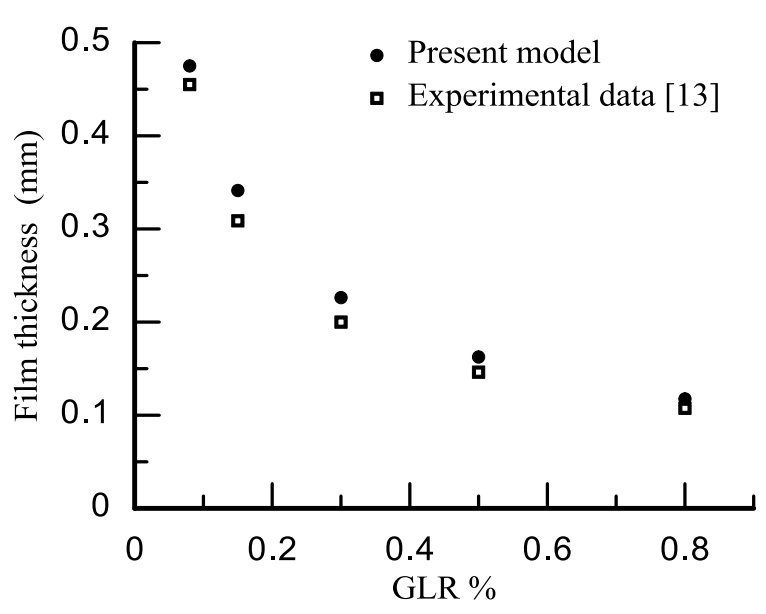

Figure.4 Comparison between calculated liquid film thickness and experimental 


\section{S. A. Wilson, A. R. Syam, A. Helmy and A. Balabel "Numerical Simulation.."}

Figure (4) compares the calculated liquid film thickness and the experimental correlation of Lin et al [13]. It is clear that the current simulated film thickness compares well with the experimental measurement. It can be depicted from figure (4) that the results of the initial guessed mesh intensity close, to great extent, to the experimental correlation. So no more mesh refinements were needed.

\subsection{Jatropha Biofuel Results}

The following is devoted to explore the possibility of using effervescent atomizer with Jatropha biodiesel compared with the standard aviation Jet A1 fuel. The effects of GLR on internal two-phase flow evolution and liquid film thickness are investigated. Further, the results are compared with Jet-A1 fuel.

Table (2) summarizes the Jatropha biodiesel properties compared with conventional commercial aviation Jet-A1 fuel [25] at temperature of 10 degree centigrade, to slightly close most of the field aviation conditions.

The volume flow rate of Jatropha biodiesel was kept constant at $0.38 \mathrm{~L} / \mathrm{min}$ and the aerating gas was selected to be the air. The volume flow rate of the gas was varied to obtain the required GLR.

The GLRs range and the corresponding flow rates and velocities for liquid and gas are tabulated in table (3). The upper limit of GLR is $0.8 \%$ was constrained by the compressibility effects associated with high velocities. The calculations were performed with variable time step ranging from $2 \mu$ sec to $1 \mathrm{n} \mathrm{sec}$.

Table (2) Properties of Jatropha biodiesel compared with conventional Jet A-1 fuel.

\begin{tabular}{lcc}
\hline Properties & $\begin{array}{c}\text { Jatropha } \\
\text { biodiesel }\end{array}$ & Jet-A1 \\
\hline Density $\left(\mathrm{kg} / \mathrm{m}^{3}\right)$ & 874 & 815 \\
Viscosity $(\mathrm{kg} / \mathrm{m} . \mathrm{s}) \times 10^{-3}$ & 4.4556 & 1.0254 \\
Surface tension $(\mathrm{N} / \mathrm{m}) \times 10^{-3}$ & 30.5 & 23.8 \\
\hline
\end{tabular}

Figure (5) shows the gas fraction volume rendering for GLR of $0.08 \%$. At this low GLR, the gas flows in the mixing chamber as a continuous jet without any disintegration. This can be attributed to the separation zone behind the aerating tube. At this zone the surface tension dominates over the low drag force. At the discharge passage inlet, the liquid velocity is increased due to the converging part. The increased velocity shatters the gas into bubbles at discharge passage inlet. These bubbles further evolve to form gas slugs.

So the flow can be identified as gas slugs separated with liquid. It can be noticed that the slugs are elongated on their way to the exit, due to the high shear and pressure reduction [15]. Lin et al [13]

Table (3). Jatropha biodiesel and air velocities and mass flow rate at different GLR

\begin{tabular}{ccccc}
\hline $\begin{array}{c}\text { GLR } \\
(\%)\end{array}$ & $\begin{array}{c}\text { Jatropha } \\
\text { mass flow } \\
\text { rate(kg/s) }\end{array}$ & $\begin{array}{c}\text { Jatropha } \\
\text { velocity } \\
(\mathbf{m} / \mathbf{s})\end{array}$ & $\begin{array}{c}\text { Air mass } \\
\text { flow rate } \\
(\mathbf{k g} / \mathbf{s})\end{array}$ & $\begin{array}{c}\text { air } \\
\text { velocity } \\
(\mathbf{m} / \mathbf{s})\end{array}$ \\
\hline 0.08 & $5.53 \mathrm{E}-3$ & 0.58 & $4.42 \mathrm{E}-6$ & 7.96 \\
0.15 & $5.53 \mathrm{E}-3$ & 0.58 & $8.85 \mathrm{E}-6$ & 15.93 \\
0.30 & $5.53 \mathrm{E}-3$ & 0.58 & $1.66 \mathrm{E}-5$ & 29.88 \\
0.50 & $5.53 \mathrm{E}-3$ & 0.58 & $2.76 \mathrm{E}-5$ & 49.80 \\
0.80 & $5.53 \mathrm{E}-3$ & 0.58 & $4.42 \mathrm{E}-5$ & 79.69 \\
\hline
\end{tabular}

reported intermittent spray for slug flow regime.

The nature of intermittent spray associated with slug flow is that one of the two phases; gas or liquid, occupies the total cross section. So the other phase has no place in that region, resulting of pure flow of the dominant phase. The most noising effect starts on atomizer exit. Series of gas slugs followed by liquid slugs exit the nozzle in sequential order. When the turn is on gas slugs, no fuel can exit and hence no spray is formed until the turn back to the following liquid slug and so on cyclic nature for spray. Figure (6) shows the gas volume fraction in discharge passage at two different times, to indicate the effect of slug flow. In figure (6-b) pure liquid exists at atomizer exit

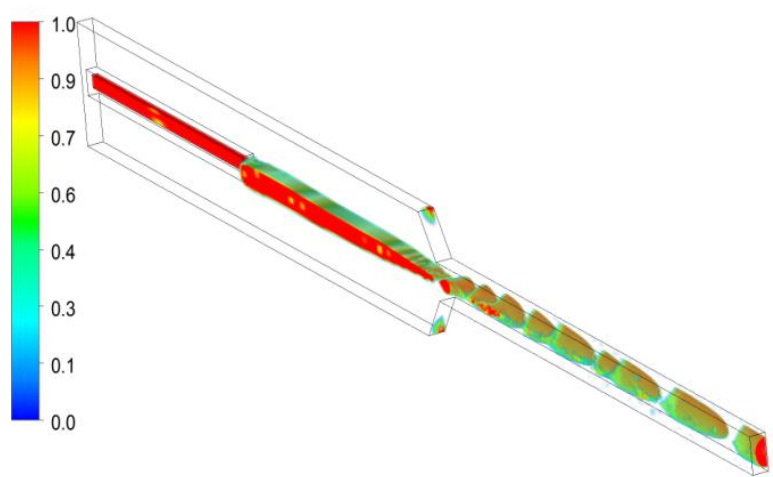

Figure.5 Gas volume fraction at $0.0564 \mathrm{sec}$ and $\mathrm{GLR}=0.08 \%$. 


\section{S. A. Wilson, A. R. Syam, A. Helmy and A. Balabel "Numerical Simulation.."}

Figure (7) shows the contour of gas volume fraction at several planes upstream outlet and at atomizer exit. It can be noticed that the gas slugs are further surrounded by liquid. The majority of mixture momentum is centred in the core region as indicated by mixture velocity contour in figure (8).

The low gas velocity inhibits the mixing between the gas and the liquid. It is obvious that the phases flow in uniform smooth manner with low mixing levels, as gas has no enough energy to disperse through liquid.

With increasing GLR to $0.5 \%$, the gas velocity increases. Figure (9) shows the gas fraction volume rendering at GLR 0.5. The gas can be identified as large bubbles in the mixing chamber, due to the increased gas quantity entering the liquid. These gas bubble squeeze the liquid in the mixing chamber thus increase liquid velocity and augment shear on the interface. This effect is obvious on the wavy interface between the two phases. The effect of vortex shedding on the gas flow is obvious.
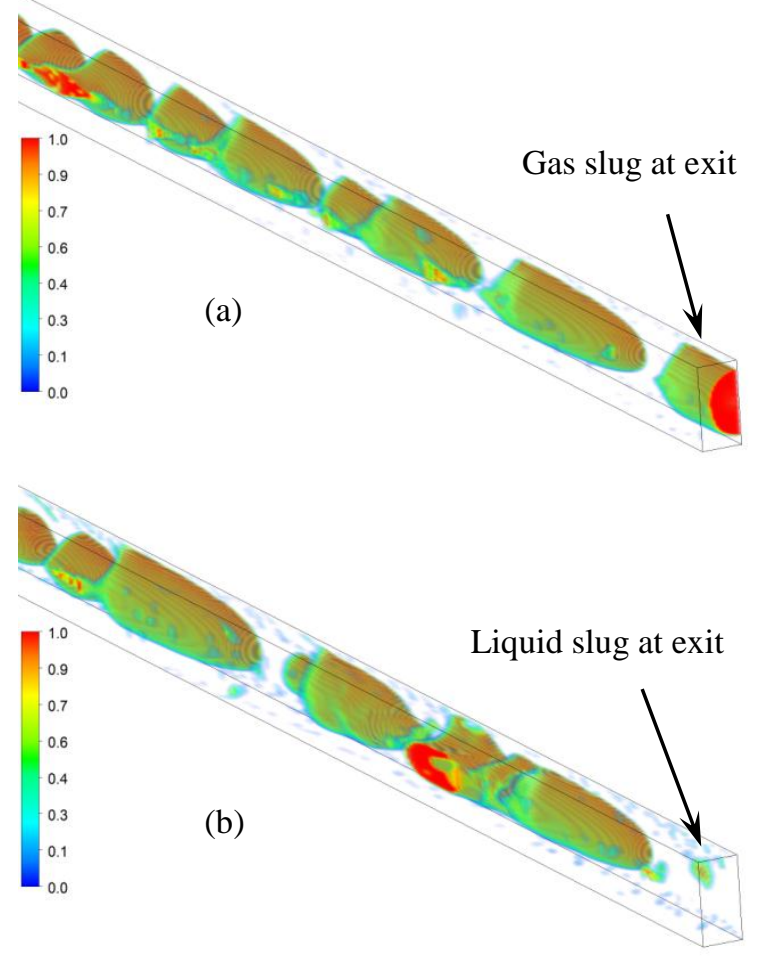

Figure.6 Gas volume fraction in discharge passage at GLR $0.08 \%$. (a) at 0.0565 s., (b) at 0.0584 s.

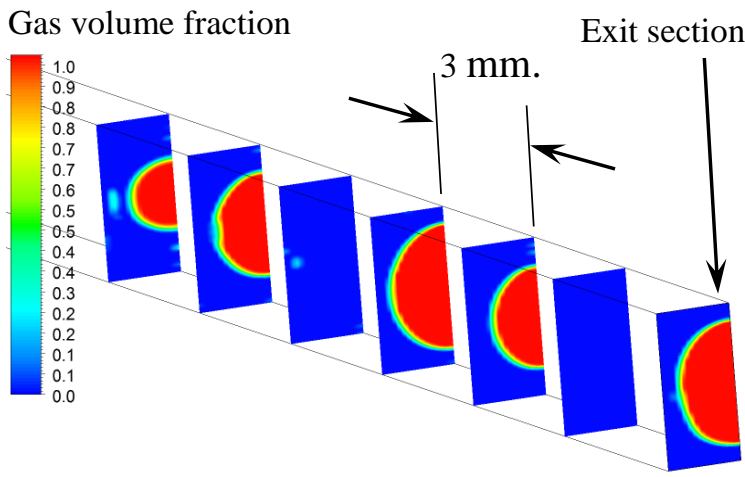

Figure.7 Gas volume fraction contours for $\mathrm{GLR}=0.08 \%$. at $0.0565 \mathrm{~s}$.

Velocity, $\mathrm{m} / \mathrm{s}$

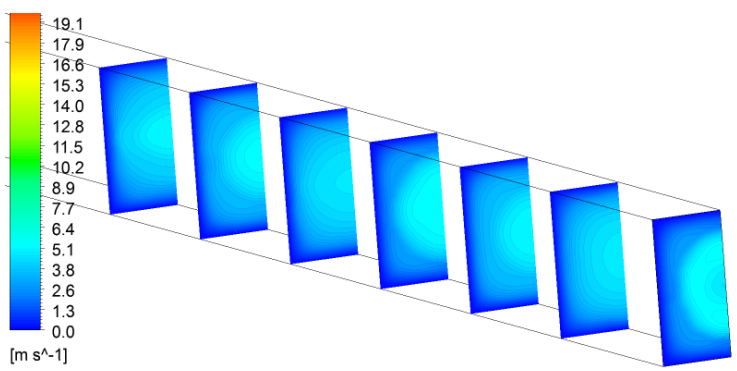

Figure.8 Mixture velocity contours. GLR $=0.08 \%$ at $0.0565 \mathrm{~s}$.

In the discharge passage, as indicated in figure (10), the gas flows as large plugs, squeezing the liquid near the wall. These plugs are further agglomerated and evolve to form annular flow due to the high shear associated with the high relative velocity. The conditions at atomizer exit can be identified as either slug flow or annular flow. The two conditions appear interchangeably as indicated in figure (10).

Gas volume fraction

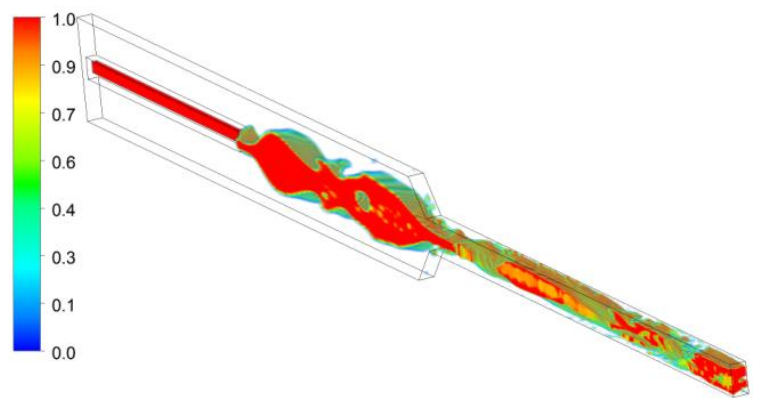

Figure.9 Gas volume fraction at $0.0341 \mathrm{~s}$. and GLR $=0.5 \%$. 


\section{S. A. Wilson, A. R. Syam, A. Helmy and A. Balabel "Numerical Simulation.."}
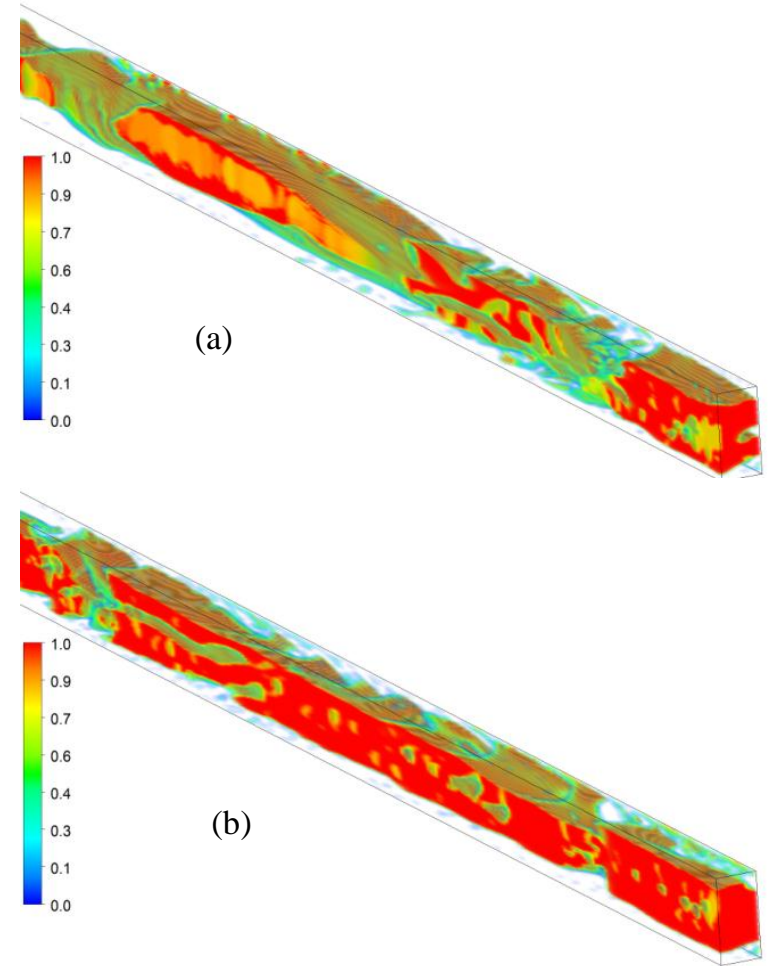

Figure.10 Gas volume fraction in discharge passage for GLR $0.5 \%$. (a) at $0.0341 \mathrm{~s}$., (b) at $0.0240 \mathrm{~s}$.

The mixing between the phases is slightly augmented with the higher gas velocity. Liquid droplets trapped in gas can be identified. Figure (11) shows the mixture turbulent intensity contours. It is clear that the mixture intensity is high at interface and gas regions due to the high relative velocity. The majority of mixture momentum is still at the core region, as indicated from the mixture velocity contours shown in figure (12).

Turbulence intensity \%

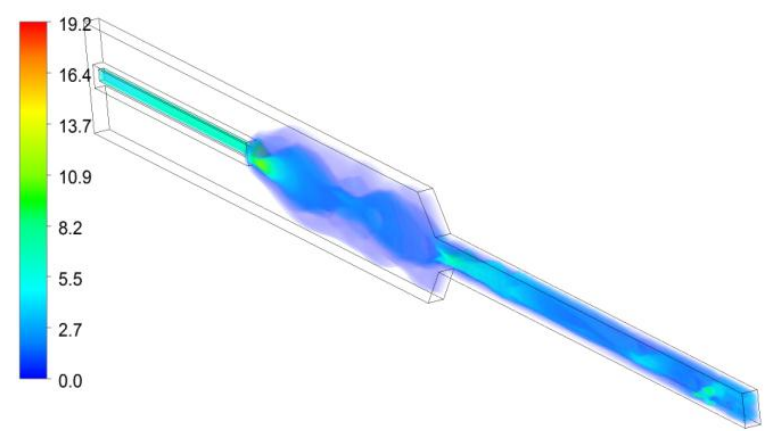

Figure.11 Mixture turbulent intensity contours for $\mathrm{GLR}=0.5 \%$, at $0.0341 \mathrm{~s}$.
Velocity, $\mathrm{m} / \mathrm{s}$

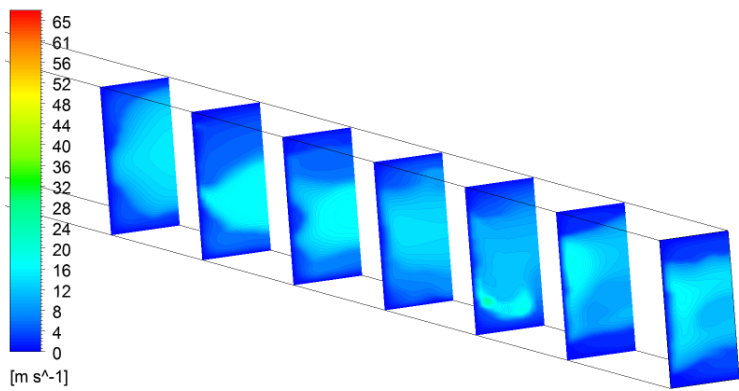

Figure.12 Mixture velocity contours for $\mathrm{GLR}=0.5 \%$, at $0.0341 \mathrm{~s}$.

Figure (13) shows the gas fraction volume rendering at GLR $0.8 \%$. The gas occupies large portion of the mixing chamber, squeezing the liquid. The squeezed liquid has higher velocity, to preserve continuity of flow, the higher relative velocity enhances shear between the two phases.

In the discharge passage a conflict on land arises between the large amount of gas and the liquid flow, which is finally settled by the gas due to the higher specific volume of gas. Forcing the liquid to squeeze in thin film near the walls surrounds the gas. Finally the dominant gas flows as annular flow surrounded by thin liquid film as shown in figure (14) indicating gas volume fraction at discharge passage. One can observe continuous stream of gas in discharge passage.

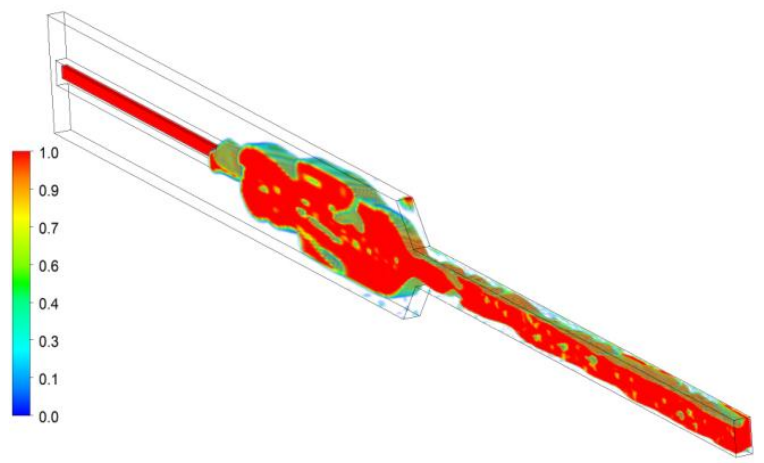

Figure.13 Gas volume fraction in discharge passage for GLR $0.8 \%$, at $0.0236 \mathrm{~s}$. 


\section{S. A. Wilson, A. R. Syam, A. Helmy and A. Balabel " Numerical Simulation.."}

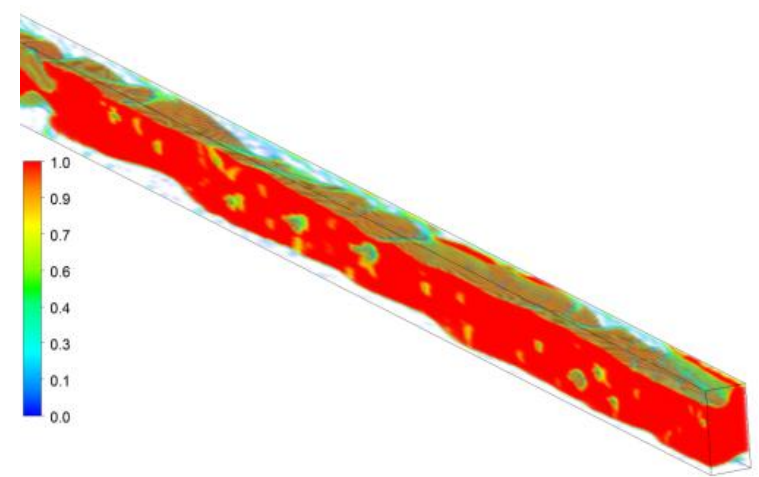

Figure.14 Gas volume fraction in discharge passage for GLR $0.8 \%$. at $0.0236 \mathrm{~s}$.

Due to the high relative velocity, the gas is exposed to excessive shear. Significant mixing between the two phases is noticed at this aeration level. Separated liquid droplet and ligaments in gas and gas bubbles in liquid can be distinguished, as shown in figure (15).

The higher mixing is obvious in the vortex zone indicated in figure (16). Lin et al [13] reported that enhanced atomization can be obtained at annular flow regime without any intermittency of the spray. The pressurized gas volumes in the discharge passage are like a timed bomb that will be sparked by the sudden pressure relief on leaving the nozzle. These violent explosions of the bubbles act as internal shattering forces cutting the liquid fuel into small ligaments and drops.

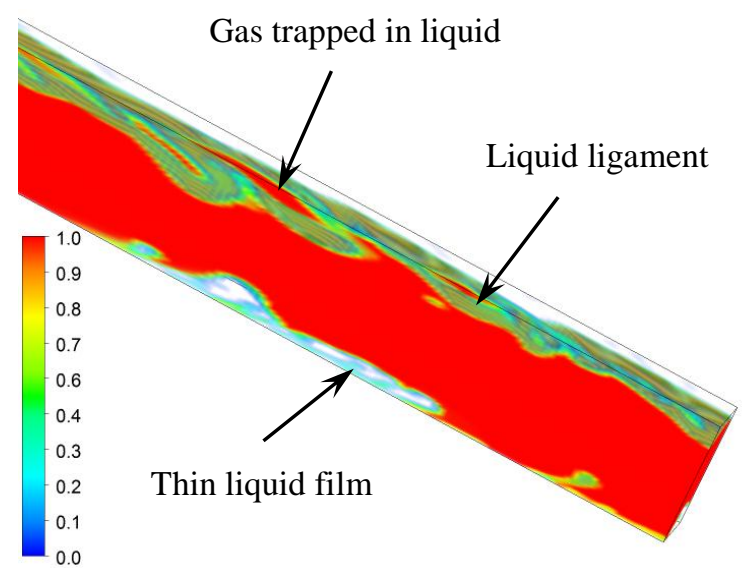

Figure.15 Gas volume fraction near exit for $\mathrm{GLR}=0.8 \%$, at $0.0245 \mathrm{~s}$

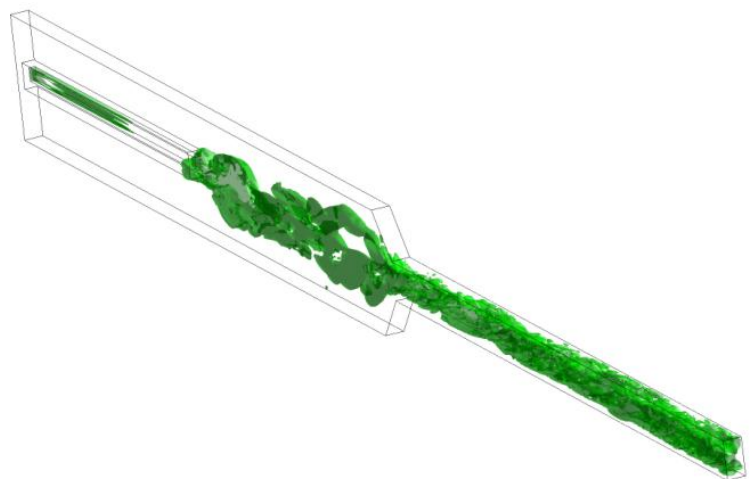

Figure.16. vortex in flow at time $=0.0245 \mathrm{sec}$.

\subsection{Liquid Film Thickness}

For all the range of the GLRs encountered in table (2), the liquid film thickness was calculated by the technique developed by Esfarjani et al. [18]. The area weighted average of liquid film thickness at the exit cross section was sampled each time step. The data extraction started when a cyclic nature of the flow was reached and continued for a period of $3 \mathrm{~ms}$, then the data was averaged over the sampling period equal $3 \mathrm{~ms}$.

Figure (17) shows the calculated film thickness for both Jatropha biodiesel and Jet-A1 fuels with different GLRs at the same flow rate.

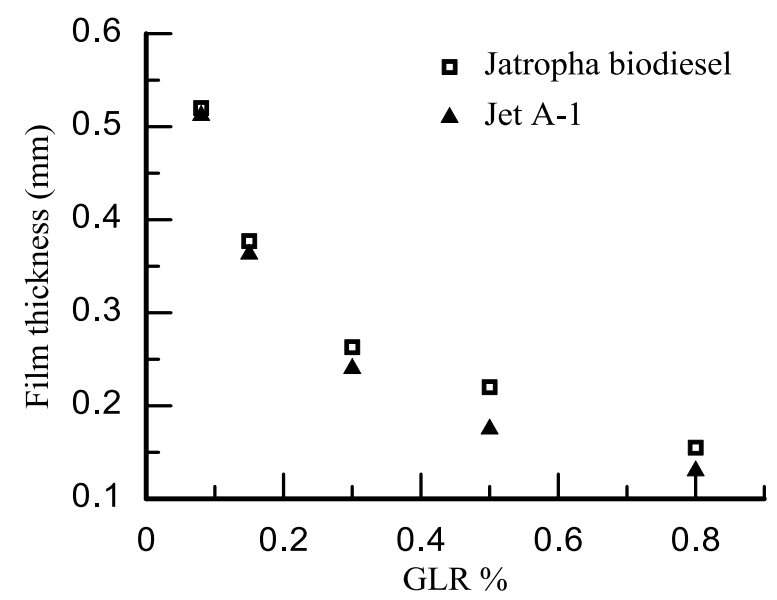

Figure.17 Comparison between liquid film thickness for Jatropha biofuel and Jet-A1 aviation fuel.

At low GLR, the liquid film thickness almost remains unchanged even though the higher viscosity and surface tension of biofuel. This is attributed to the nature of the flow as bubbly and slug flow. The 


\section{S. A. Wilson, A. R. Syam, A. Helmy and A. Balabel "Numerical Simulation.."}

higher surface tension of Jatropha biodiesel leads to larger bubbles diameter. The larger bubbles experience higher shear in the discharge passage leading to elongated bubbles. This balances the smaller bubbles produced for Jet-A1 fuel. So the liquid film thickness almost remains constant at low GLRs.

Increasing the GLR, the flow evolves to annular flow and no separated bubbles are distinguished in the discharge passage. So the liquid film thickness of biofuel is slightly higher due to the higher surface tension. But this leads to increasing gas velocity, which slightly augments atomization. However, with further increase of GLR, the liquid film thickness of the biofuel closes to the Jet-A1 results. This is attributed to the thin liquid film squeezed near wall and majority of discharge passage is occupied with gas.

This result reveals the superiority of effervescent atomizer in handling high viscosity biofuels.

\section{CONCLUSION}

In the current study, structure of internal two-phase flow inside effervescent atomizer was studied numerically. Three dimensional simulation was performed using the volume of fluid model. The main purpose of simulation was to investigate the replacement of conventional aviation fuel, jet-A1, by Jatropha biofuel, as alternative renewable fuel. Validation with experimental measurement was performed and the results compared well, following the same trend. The liquid film thickness was also calculated with statistical averaging. For Jatropha biofuel simulation the following points can be concluded;

- The two-phase flow structure is affected by GLR to great extent.

- For low GLR (0.08\%) slug flow is identified.

- Increasing GLR turns the flow to annular flow.

- Mixing between fuel and gas is enhanced with higher GLR.

- The liquid film thickness changes rapidly with low GLR range.

- Comparing liquid film thickness of Jatropha biofuel and Jet-A1, slight change is identified.

This leads to the superiority of effervescent atomizer for handling the high viscosity biofuel and supporting using Jatropha biofuel as alternative in commercial aviation applications. But, still simulation of external spray is needed for full investigation.

\section{Nomenclature}

$\begin{array}{ll}\mathrm{D} & \text { Diameter }(\mathrm{m}) \\ \mathrm{f} & \text { Surface tension force }(\mathrm{N}) \\ \mathrm{g} & \text { Gravitational acceleration }\left(\mathrm{m} / \mathrm{s}^{2}\right) \\ \mathrm{h} & \text { Liquid film thickness }(\mathrm{m}) \\ \mathrm{k} & \text { Turbulent kinetic energy }\left(\mathrm{m}^{2} / \mathrm{sec}^{2}\right) \\ p & \text { Pressure }\left(\mathrm{N} / \mathrm{m}^{2}\right) \\ \mathrm{R} & \text { Radius }(\mathrm{m}) \\ \mathrm{S} & \text { Source terms }(\mathrm{N} . \mathrm{sec}) \\ \mathrm{t} & \text { Time }(\mathrm{sec}) \\ \mathrm{U} & \text { Velocity vector }(\mathrm{m}) \\ \mathrm{u} & \text { Velocity component in } \mathrm{X}-\mathrm{axis}(\mathrm{m}) \\ \mathrm{v} & \text { Velocity component in } \mathrm{y}-\mathrm{axis}(\mathrm{m}) \\ \mathrm{w} & \text { Velocity component in } \mathrm{Z}-\mathrm{axis}(\mathrm{m}) \\ \mathrm{X} & \text { Coordinate axis } \\ \mathrm{y} & \text { Coordinate axis } \\ \mathrm{Z} & \text { Coordinate axis } \\ & \\ \mathrm{Greek} & \text { symbols } \\ \varepsilon & \text { Turbulent dissipation rate }\left(\mathrm{m}^{2} / \mathrm{sec}^{3}\right) \\ \rho & \text { Density }\left(\mathrm{kg} / \mathrm{m}^{3}\right) \\ \phi & \text { General variable } \\ \Gamma & \text { Diffusion coefficient } \\ \mu & \text { Dynamic viscosity }(\mathrm{pa} . \mathrm{sec}) \\ \sigma & \text { Surface tension coefficient }(\mathrm{N} / \mathrm{m}) \\ \alpha & \text { Volume fraction } \\ \kappa & \text { Interface curvature } \\ & \end{array}$




\section{S. A. Wilson, A. R. Syam, A. Helmy and A. Balabel "Numerical Simulation.."}

\section{REFERENCES}

[1] Lefebvre A. H. and Dilip R. B., " Gas turbine combustion alternative fuel and emissions ", CRC press, 2010.

[2] Thierry P. and Denis V., " Theoretical and Numerical Combustion ", Second Edition, R.T. Edwards Inc, 2005.

[3] Antony S. R., "Biodiesel production from Jatropha oil and its characterization", Research Journal of Chemical Sciences, 2011.

[4] Lefebvre A. H, " Atomization and Sprays", Hemisphere, New York, 1989.

[5] Altin, R., Cetinkaya, S. and Yücesu., " The Potential of Using Vegetable Oil Fuels as Fuel for Diesel Engines", Energy Conversion and Management, Vol. 42, pp. 529-538, 2001.

[6] Farag M. S., Shabana H. M., Wilson S. A. , ElAskary A. H., " Investigation into the Performance of Diesel Engines Using Blends of Waste Vegetable Oils", ICFD conference , 2008.

[7] Lefebvre A. H., "A Novel Method of Atomization with Potential Gas Turbine Application", Indian Defense Sci, Vol. 38, pp. 353-62, 1988.

[8] Lefebvre A. H., Wang X. F. and Martin, C.A. "Spray Characteristics of Aerated-Liquid Pressure Atomizers", AIAA J. Prop Power, Vol. 4, No. 4, pp. 2938., 1988.

[9] Buckner H. E. and Sojka P. E., "Effervescent Atomization of High Viscosity Fluids. Part 1: Newtonian Liquids", Atomization and Sprays, Vol. 1, pp. 239-52,1991.

[10] Sovani S.D., Sojka P. E. and Lefebvre A. H. "Effervescent Atomization", Prog. Energy Combust. Sci., Vol. 27, pp. 483-521, 2001.

[11] Roesler T. C. and Lefebvre A. H., "Photographic studies on aerated liquid atomization", combustion fundamentals and applications. Proceedings of the Meeting of the Central States Section of the Combustion Institute, Indianapolis, Indiana, Paper 3, 1988.

[12] Chin J. S. and Lefebvre A. H., " Flow patterns in internal-mixing, twin-fluid atomizers", Atomization and Sprays, vol 3 , 463-475,1993.

[13] Lin K. C., Kennedy P. J. and Jackson T. A. "Structures of Internal Flow and the
Corresponding Spray for Aerated-Liquid Injectors", AIAA Paper 2001-3569, 2001.

[14] Huang X. , Wang X. and Liao G. "Visualization of Two Phase Flow inside an Effervescent Atomizer", Journal of Visualization, Vol. 11 No. 4, pp.299-308, 2008.

[15] Marc L., Florian S. and Dieter M.," Flow field and phase distribution inside effervescent atomizers ", ILASS-Europe, 2003.

[16] Madan A. M. , Devendra D., Anand T. N. C., and Ravikrishna R. V.," Effervescent Spray Characterization of Jatropha Pure Plant Oil", ILASS - Europe 2010, 23rd Annual Conference on Liquid Atomization and Spray Systems, Brno, Czech Republic, September 2010.

[17] Tian. A., "Numerical Simulation of Transient Two-Phase Flow within Aerated-Liquid Injectors", AIAA Paper 2003-4266, 2003.

[18] Esfarjani S A, and Dolatabadi A, "A 3D simulation of two-phase flow in an effervescent atomizer for suspension plasma spray", Surf Coatings Tech, 2009, 203: 2074-2080.

[19] Mehmood K. and Masud J.," Analysis of TwoPhase Flow in an Effervescent Atomizer Using Volume of Fluid Method", AIAA paper, 0312 , 2012.

[20] Shih T.-H., Liou W. W., Shabbir A., Z. Yang, and Zhu J. "A New Eddy-Viscosity Model for High Reynolds Number Turbulent Flows Model Development and Validation". Computer and Fluid. 24(3). 227-238. 1995.

[21] Hirts C. W. and Nicholas B. D., "Volume of fluid (VOF) method for the dynamic of free boundaries", journal of computational physics, 39,201-255,1981.

[22] Brackbill J. U., Kothe D. B. and Zemach, "A Contin-mium method for modeling surface tension", Journal of computational physics, 100,335-354,1992.

[23] FLUENT, Computational Fluid Dynamics Software Package, Ver. 6.3.26, Fluent Inc, Lebanon, NH.

[24] FLUENT, Computational Fluid Dynamics Software Package User Guide, Ver. 6.3, Fluent Inc, Lebanon, NH.

[25] "Aviation Fuel Properties", coordinating research council, Georgia, 1983. 